Research paper

\title{
An organoclay formula for the slow release of soluble compounds
}

\author{
Guodong Yuan* \\ Yantai Institute of Coastal Zone Research, Chinese Academy of Sciences, 17 Chunhui Road, Yantai, Shandong 264003, PR China
}

\section{A R T I C L E I N F O}

\section{Article history:}

Received 19 November 2013

Received in revised form 31 March 2014

Accepted 4 April 2014

Available online 24 April 2014

\section{Keywords:}

Organoclays

Nanoclays

Slow-release formula

Fertilizer

DCD

\begin{abstract}
A B S T R A C T
Slow-release formulations have been developed to enhance the effective use of active ingredients. In the case of fertilizers the formulations reduce nutrient leaching and greenhouse gas emissions. While polymer-coating is the dominant technology in producing slow-release fertilizers there is a demand for alternative options for different usages. To this end, a commercially available organoclay, with a basal spacing of $3.67 \mathrm{~nm}$, was used as matrix to produce pellets of $\mathrm{CuSO}_{4}$ and dicyandiamide (DCD) of different sizes by a die set and hand press. Both $\mathrm{CuSO}_{4}$ and DCD pellets showed a good slow-release performance in dissolution tests. Large pellets $(1.2 \mathrm{~cm}$ in diameter) of $\mathrm{CuSO}_{4}$ had a better performance in slow-release than small ones $(0.7 \mathrm{~cm})$. For DCD pellets $(0.7 \mathrm{~cm}$ in diameter) it took 6 days for a complete dissolution. The slow-release effect is probably due to the hydrophobic nature and high aspect ratio of the organoclay. The former makes soluble compounds between organoclay particles less susceptible to dissolution in water, whereas the latter hinders the dissolution of solutes inside a pellet by making their diffusion passage tortuous. The organoclay formulation is easy to make, and the rate of solute release can be adjusted by changing pellet size.
\end{abstract}

(c) 2014 Elsevier B.V. All rights reserved.

\section{Introduction}

Organically modified clay minerals ("organoclays") are formed through ion exchange where inorganic cations $\left(\mathrm{Na}^{+}, \mathrm{Ca}^{2+}\right)$ at the surface of clay minerals (e.g., montmorillonite) are replaced by organic cations, of which quaternary ammonium cations (QAC) are the most commonly used ones. This intercalation of organic cations results in three properties: it renders clay minerals hydrophobic (or organophilic), enlarges the interlayer space of clay minerals, and provides sites for the retention of non-ionic organic compounds (NOC) through the hydrophobic tail of QAC. These properties have been extensively exploited for a wide range and a variety of applications (de Paiva et al., 2008), from rheological control agents, paints, and grease to cosmetics and personal care products. The most important applications in the last two decades have been the use of organoclays in polymer-clay nanocomposites and as adsorbents of NOC, which are the subjects of two recent reviews of Bergaya et al. (2013) and Yuan et al. (2013), respectively.

The search for new applications of organoclays does not stop with the above-mentioned nanocomposites and adsorbents. Here is a report on the development of an organoclay formula for the slow release of soluble compounds, with a focus on soluble chemical fertilizers: $\mathrm{Cu}$ as a trace element nutrient and dicyandiamide ( $D C D, \mathrm{H}_{4} \mathrm{C}_{2} \mathrm{~N}_{4}$ ) as a nitrification inhibitor and nitrogen source. Chemical fertilizers are essential to produce enough food to feed 7 billion people in the world. However, their huge environmental impacts, from nutrient leaching and eutrification to nitrous oxide (a greenhouse gas) emission, determine

\footnotetext{
* Tel.: +8 6535 2109238; fax: +865352109000

E-mail address: gdyuan@yic.ac.cn.
}

that a greater efficiency has to be achieved in fertilizer use (Chien et al., 2009). Among other things, slow-release fertilizers have been developed and widely used to improve fertilizer use efficiency. They are commonly produced by forming a polymer coating on fertilizer grains. The complicated production processes, involving heating and size separation of fertilizers, and melting and nebulization of polymers, are among the factors that make slow-release fertilizers expensive (Trenkel, 2010). Further, their use may lead to an undesirable accumulation of plastic residues, up to $50 \mathrm{~kg} / \mathrm{ha} / \mathrm{yr}$. Indeed, plastic residue in drainage from paddy field causes problems to fish. Thus, demands exist for alternative technologies to produce slow-release fertilizers. The hydrophobic nature of organoclays suggests their suitability as a matrix for slow-release of soluble compounds. The purpose of this research was to demonstrate that this was technically feasible.

\section{Materials and methods}

A commercially available organoclay, formed by the reaction of sodium montmorillonite with octadecyltrimethyl ammonium chloride, was obtained from Fenghong New Materials Ltd, China and used as is in this study. The XRD patterns of the organoclay were obtained by packing it into an aluminium sample holder, and scanning from 2 to $14^{\circ}$ of $2 \theta$ at a rate of $2^{\circ} / \mathrm{min}$. A Philips PW1710 XRD diffractometer with a PW $1050 / 80$ goniometer and $\operatorname{CoK} \alpha$ radiation $(\lambda=0.1790 \mathrm{~nm})$ was used.

TA Instruments ${ }^{\circledR}$ Q600 SDT thermal analyzer was used for high resolution thermogravimetric analysis (TGA), differential thermal analysis (DTA), and differential scanning calorimetry (DSC). The organoclay $(20 \mathrm{mg}$ ) was heated in nitrogen atmosphere from room temperature 
to $600{ }^{\circ} \mathrm{C}$ at a heating rate of $10{ }^{\circ} \mathrm{C} / \mathrm{min}$. Details of the methodology were described elsewhere (Hedley et al., 2007).

Copper sulphate pentahydrate of analytical grade $\left(\mathrm{CuSO}_{4} \cdot 5 \mathrm{H}_{2} \mathrm{O}\right)$ was ground to powder with an agate pestle and mortar, and dry mixed with the organoclay (at a ratio of $14.644 \mathrm{~g} / 60.00 \mathrm{~g}$ ) to give a final $\mathrm{Cu}$ concentration of $5.00 \%$. The mixture was then made into large and small pellets ( 1.2 and $0.7 \mathrm{~cm}$ in diameter, respectively) of about 0.58 and $0.29 \mathrm{~g}$ each using a die set and hand press. The slow-release pellets $(0.7 \mathrm{~cm}, 0.20 \mathrm{~g})$ of dicyandiamide (DCD)-organoclay were made in a similar way, with a DCD content of 10,20 , or $40 \%$.

The slow-release performance of the organoclay formula was assessed by dissolution tests at room temperature $\left(21^{\circ} \mathrm{C}\right)$. $\mathrm{CuSO}_{4}{ }^{-}$ organoclay pellets of similar weights (1.1594 vs. $1.1409 \mathrm{~g}$ ) but different sizes ( $1.2 \mathrm{vs.} 0.7 \mathrm{~cm}$ ) were placed in plastic vials with $1 \mathrm{mM} \mathrm{CaCl}_{2}$ solution as background electrolyte. The pellet:solution ratio was 1:20 (weight:volume) as specified in some test methods for slow-release fertilizers (Trenkel, 2010). The solution was replaced after 2, 7, 12, 24, 48, and 96 $\mathrm{h}$, filtered through $0.45 \mu \mathrm{m}$, and analyzed by atomic absorption spectrometry for $\mathrm{Cu}$ concentration. The dissolution test for DCD-organoclay pellets was conducted in triplicate in plastic vials with one pellet and $20 \mathrm{~mL}$ of deionized water in each. The water was replaced after 2, 8, 24, 48, 72, 96,120 , and $144 \mathrm{~h}$, filtered through $0.45 \mu \mathrm{m}$, and analyzed for DCD concentration by HPLC (Waters Inc.) using a cation-H guard column and a $210 \mathrm{~nm}$ UV detector (Schwarzer and Haselwandter, 1996). At the end of dissolution tests organoclay pellets remained visually intact.

\section{Results and discussion}

The organoclay used in this study was an organically modified montmorillonite, with a basal spacing of $3.674 \mathrm{~nm}$ (Fig. 1). In other words, it had an interlayer space of about $2.67 \mathrm{~nm}$. It was hydrophobic and contained only a small amount of water $(<3 \%)$, as measured by the weight loss (Fig. 2) at $105{ }^{\circ} \mathrm{C}$. Its onset temperature of decomposition was about $259.8^{\circ} \mathrm{C}$ and upon heating its organic component (36.9\% by weight) started to decompose and disappeared by $500{ }^{\circ} \mathrm{C}$.

The dissolution curve of $\mathrm{CuSO}_{4}$-organoclay pellets is shown in Fig. 3. Compared with the instant dissolution of pure $\mathrm{CuSO}_{4}$ pellets (the control) the organoclay formula clearly demonstrated its ability to release $\mathrm{CuSO}_{4}$ slowly. The smaller pellets released $\mathrm{CuSO}_{4}$ faster than the larger ones. Thus, the release rate can be adjusted by changing the size of pellets to suit the requirements of end users, which would be an advantage from the production point of view.

This ability of the organoclay in slowly releasing soluble compounds is underpinned by its hydrophobic nature and large aspect ratio. Organoclays are hydrophobic, i.e., they tend to expel water molecules rather than attract them when placed in water. Thus, it would be more difficult for water to dissolve solute molecules sandwiched between two organoclay particles than the same molecules in pure compound. The high aspect ratio of organoclays further enhances their suitability as a universal matrix in fertilizer formulae for the slow release of soluble compounds. A unit layer of montmorillonite can be up to $2 \mu \mathrm{m}$ in length and about $1 \mathrm{~nm}$ in thickness. Thus, its aspect ratio can be as high as 2000 . When subject to applied directional stress, the high aspect ratio of organoclay causes the particles to align so that the long axes are mostly parallel. This makes it difficult for water molecules to enter an organoclay pellet because they have to follow the tortuous passage inside the pellet rather than take the shortest direct path. This effect is similar to that of organoclay in polymer-clay nanocomposites achieving excellent gas-barrier property, as illustrated by Bharadwaj (2001).

The release of DCD from organoclay formula (Fig. 4) showed a rapid initial rate and a gradually decreased rate with time. It took about 6 days for a complete dissolution of DCD in the pellet. Figs. 3 and 4 show the same type of dissolution characteristics. This is not surprising given that the dissolution starts on the outer surface of a pellet where $\mathrm{CuSO}_{4}$ or DCD molecules are exposed to water and the initial dissolution is not limited by diffusion. With time water penetrates through the cavity left by solute dissolution into the inner part of the pellet where $\mathrm{CuSO}_{4}$ or DCD molecules dissolve and then migrate outside to bulk solution. The rate of dissolution is limited by diffusion rate. The farther from the outer surface of a pellet, the longer it would take for inner solutes to dissolve and migrate outward, i.e., the slower the dissolution rate of solutes would be. The close percentages of DCD released from pellets of 10, 20, and $40 \%$ (conversion of Y-axis of Fig. 4 to dissolved DCD \%) clearly suggest that slow diffusion is the key mechanism for the slow-release of solutes from pellets.

Because solute dissolution from a pressed pellet is diffusion-limited pellet size would also affect the slow-release performance of solutes. This is of practical advantage to the production and application of organoclay formula for the slow release of soluble compounds. For example, pellets of larger size and thus slower release rate can be produced without the need to change the composition of pellets; it would

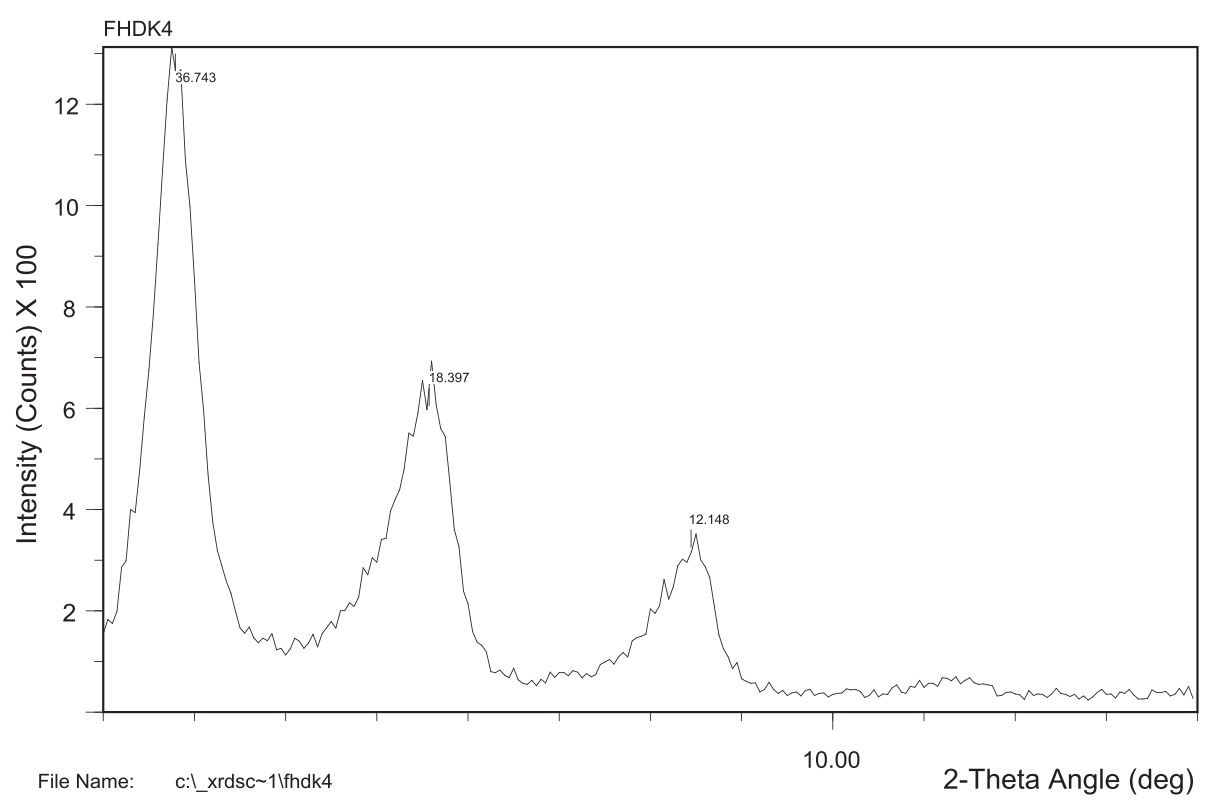

Fig. 1. X-ray diffraction patterns of the organoclay. 


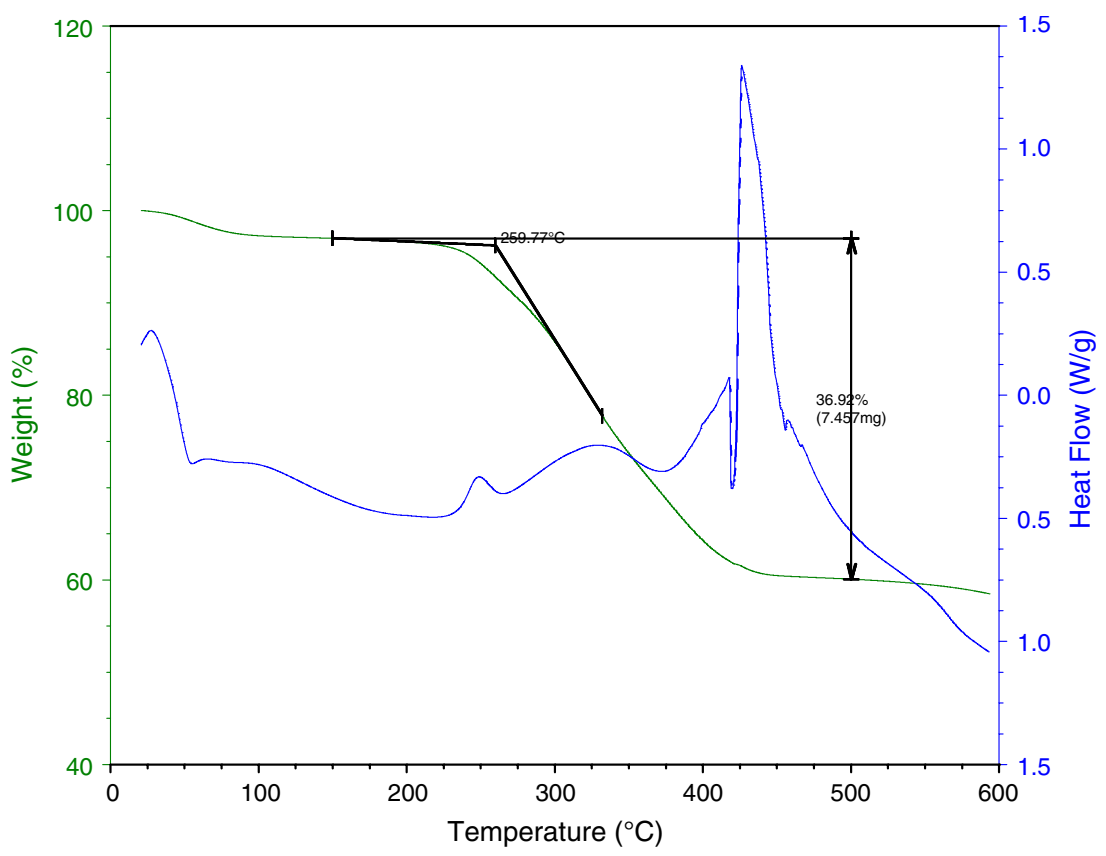

Fig. 2. Thermal analytical data of the organoclay (Exo up).

be more convenient and time-saving to place a big ball of organoclaybased slow-release fertilizer into root zone in soil than place tens or hundreds of tiny polymer-coated fertilizer grains.

In summary, the advantages of organoclay formula for slow release of soluble compounds include: 1) the nature and solubility of the compounds would be irrelevant. In other words, the formula is universally applicable to all soluble compounds. Further, a suggestion is made for future study that organoclay formula might be used as well for the delivery of poorly soluble compounds to hydrophobic plant surfaces; 2) the process for manufacturing organoclay formula of slow-release compounds is straightforward, involving only mixing and mechanical pressing. It does not require complex processes and expensive facilities; and 3) the slow-release rate can be adjusted by changing the size of end products.

To reduce cost the organic cations for producing organoclays may be derived from waste materials such as tallow from meat works. This would help make it more feasible to commercialize the organoclay formula of slow-release fertilizers.

Unlike the polymer residue from current slow-release fertilizers, the residue of organoclay in soil would be of little concern because its organic component is held in the nm space between clay mineral layers

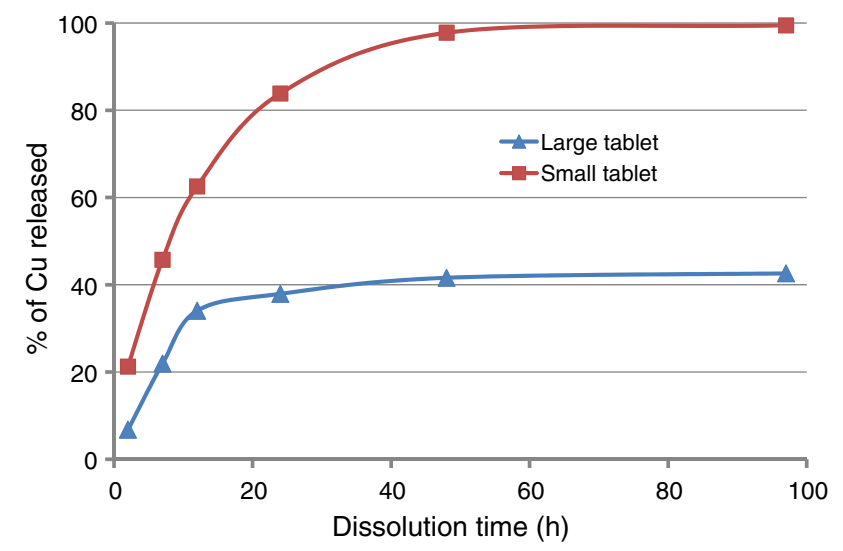

Fig. 3. The cumulative release of $\mathrm{Cu}$ ions from large $(1.2 \mathrm{~cm})$ and small $(0.7 \mathrm{~cm})$ pellets of organoclay formula with $5.00 \% \mathrm{Cu}$. and thus not accessible to microorganisms ( $\mu \mathrm{m}$ in size), and the mineral component (montmorillonite) is a naturally occurring nanoparticle in many types of soils (Theng and Yuan, 2008).

\section{Conclusions}

An organoclay was used to make slow-release formulation of soluble compounds, providing an alternative to polymer coating technology. Both $\mathrm{CuSO}_{4}$ (with a high solubility) and DCD (with a moderate solubility) in organoclay pellets showed good slow-release characteristics, suggesting that the formulation is applicable to any compounds. The slow-release effect is underpinned by the hydrophobic nature and high aspect ratio of the organoclay. The hydrophobic property makes solutes on the surface of pellets less susceptible to dissolution in water. It also makes solute in organo-phase less hydrophilic and thus a lower propensity to be associated with water phase. Solute dissolution inside pellets is further hindered by the slow diffusion via tortuous passage as a result of high aspect ratio. Organoclay pellets are easier to make than polymer-coated fertilizers, with the added advantages that the formulation is universally applicable to soluble compounds and their release rate can be adjusted by changing pellet size.

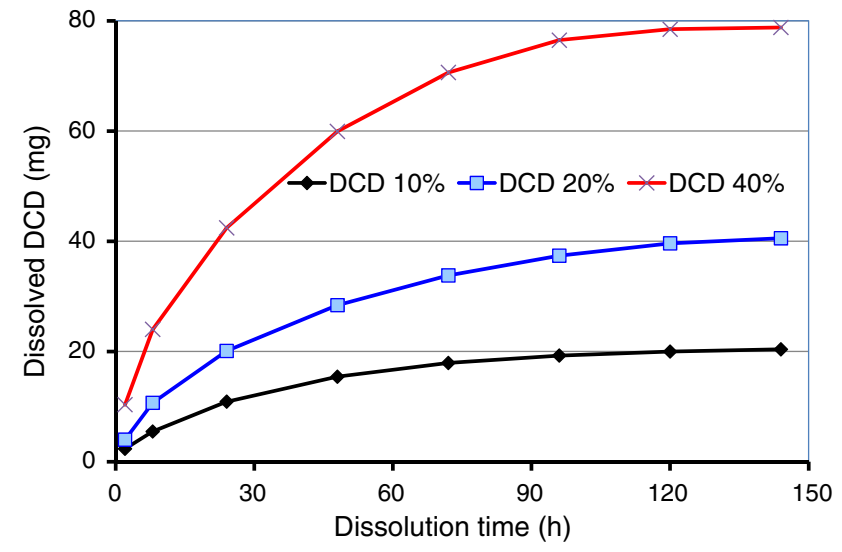

Fig. 4. The cumulative release of DCD from its organoclay formula in water. 


\section{References}

Bergaya, F., Detellier, C., Lambert, J.-F., Lagaly, G., 2013. Introduction to clay-polymer nanocomposites (CPN), In: Bergaya, F., Lagaly, G. (Eds.), Handbook of Clay Science, 2nd ed. Elsevier, Amsterdam, pp. 655-677.

Bharadwaj, R.K., 2001. Modeling the barrier properties of polymer-layered silicate nanocomposites. Macromolecules 34, 9189-9192.

Chien, S.H., Prochnow, L.I., Cantarella, H., 2009. Recent developments of fertilizer production and use to improve nutrient efficiency and minimize environmental impacts. Adv. Agron. 102, 267-322.

de Paiva, L.B., Morales, A.R., Diaz, F.R.V., 2008. Organoclays: properties, preparation and applications. Appl. Clay Sci. 42, 8-24.
Hedley, C.B., Yuan, G.D., Theng, B.K.G., 2007. Thermal analysis of montmorillonites modified with quaternary phosphonium and ammonium surfactants. Appl. Clay Sci. 35, 180-188. Schwarzer, C., Haselwandter, K., 1996. Rapid quantification of the nitrification inhibitor dicyandiamide in soil samples, nutrient media and bacterial cell-free extracts. J. Chromatogr. A 732, 390-393.

Theng, B.K.G., Yuan, G.D., 2008. Nanoparticles in the soil environment. Elements 4, 395-399. Trenkel, M.E., 2010. Slow- and Controlled-release and Stabilized Fertilizers: an Option for Enhancing Nutrient Efficiency in Agriculture, 2nd ed. International Fertilizer Industry Association, Paris, France (160 pp.)

Yuan, G.D., Theng, B.K.G., Churchman, G.J., Gates, W.P., 2013. Clays and clay minerals for pollution control, part B: techniques and applications, In: Bergaya, F., Lagaly, G. (Eds.), Handbook of Clay Science, 2nd ed. Elsevier, Amsterdam, pp. 587-644. 